\title{
Evaluation of Quality of Life, Anxiety and Depression in Patients with Recurrent Aphthous Stomatitis
}

\author{
(1) Ümran Öner'1, (1) Fatih Öner², (1) Osman Kurt³ , (D Şevki Özdemir4 \\ ${ }^{1}$ Kastamonu University School of Medicine, Department of Dermatology, Kastamonu, Turkey \\ ${ }^{2}$ Kastamonu University School of Medicine, Department of Otorhinolaryngology, Kastamonu, Turkey \\ ${ }^{3}$ Adıyaman Provincial Heath Directorate, Department of Public Health, Adıyaman, Turkey \\ ${ }^{4}$ Erzincan Binali Yıldırım University Faculty of Medicine, Department of Dermatology, Erzincan, Turkey
}

\section{Abstract}

Objective: Recurrent aphthous stomatitis (RAS) is one of the most common diseases of the oral mucosa characterized by recurrent painful oral ulcers. We evaluated the effect of RAS on quality of life and the relationship between RAS and anxiety and depression.

Methods: The study involved 70 patients (35 female, 35 male) with RAS and 70 healthy volunteers (32 females, 38 males) who matched the patients with age and gender. Demographic features and medical histories of individuals were recorded. Patients and controls filled out the dermatology quality of life index (DLQI) and the hospital anxiety and depression scale (HADS). The results were compared statistically.

Results: The DLQI score of RAS patients was significantly higher than the control group $[p<0.001$, interquartile range (IQR): $6.0-15.0$ vS. 2.0-9.0]. DLQI score for the patients during the active phase was significantly higher than that for the patients during the remission period ( $p=0.039$, IQR: 6.5-16.0 vs. 2.0-10.0). There was no significant difference in HAD score between the groups ( $p>0.05)$.

Conclusion: The results of our study show that there is no relationship between RAS and anxiety and depression. However, RAS significantly decreases the quality of life, particularly during the active phase.

Keywords: Anxiety, aphthous stomatitis, depression, oral ulcer, quality of life

\section{INTRODUCTION}

Recurrent aphthous stomatitis (RAS) is the most common disease of oral mucosa characterized with recurrent painful ulcerations. The prevalence of the disease ranges from $5 \%$ to $60 \%$ with an average of $20 \%(1,2)$. RAS can affect people at any age; oral ulcerative episodes first appear before the age of 30 years in about $80 \%$ of cases and generally, the severity and frequency decreases as age advances $(3,4)$. Approximately $40 \%$ of the patients with RAS have a family history (5). Three main types include minor, major and herpetiform aphthae which change in size, number, duration, place and potential for scarring of ulcerations. The lesions are identified by a single or multiple round or ovalshaped, inflamed ulcers, with a grayish or yellowish background, surrounded by an erythematous halo. RAS is a multifactorial condition with various predisposing factors. Investigations have proposed genetics, malnutrition, hematological deficiencies, microbial factors, immunodeficiency disorders, trauma, endocrinological, gastroenterological disorders, drugs and stress $(6,7)$. There are many studies in the literature regarding the impact of stress, anxiety, and depression in the etiology of RAS, but the results are controversial. Some authors suggest that stress and anxiety are involved in the etiology of RAS (8-10). They suggest that anxiety and severe stress trigger the immune system activity by increasing the number of leukocytes in the inflammation sites consequently, leading to onset and progression of RAS (1113). However, some authors report that there is no association

Phone: +90 3662141053 E-mail: umran.yildiz9@gmail.com ORCID ID: orcid.org/0000-0002-7119-9876

Cite this article as: Öner Ü, Öner F, Kurt 0, Özdemir \$̦. Evaluation of Quality of Life, Anxiety and Depression in Patients with Recurrent Aphthous Stomatitis. Eur Arch Med Res 2022;38(1):23-28

๑Copyright 2022 by the University of Health Sciences Turkey, Prof. Dr. Cemil Taşcıoğlu City Hospital

European Archives of Medical Research published by Galenos Publishing House. 
between the psychological status of patients and RAS (14-16). In this study, we evaluated the association between quality of life, anxiety, and depression with RAS.

\section{METHODS}

\section{Patients and Study Design}

A prospective and controlled clinical trial was planned to assess dermatology quality of life index (DLQI) and hospital anxiety and depression scale (HADS) in patients with RAS. The study was administered with the cooperation of Ataturk University Faculty of Medicine, Departments of Dermatology and Venereal Diseases. Atatürk University Faculty of Medicine Ethics Committee approved the study (number of meetings: 6, decision no: 10 , date: 30.11 .2017$)$. Seventy patients with RAS and 70 healthy controls were included between November 2017 and November 2018 after giving their informed consent.

All cases with oral aphthous ulcerations that occur more than three episodes per year were included in the RAS group after anamnesis, physical examination and laboratory evaluation. Exclusion criteria were:

1. Cases with a history of systemic condition, in particular, Behcet's syndrome, systemic lupus erythematosus or any other diseases presenting with oral mucosal findings,

2. Patients with a history of psychiatric diseases,

3. Those with a history of antimicrobial, anti-inflammatory medication, immunomodulatory agents and vitamin or antioxidant drug usage through the four weeks before the study.

The control group consisted of age and sex-matched healthy 70 people. They were selected from hospital staff, students and relatives without any systemic and psychiatric diseases.

Personal data and anamnesis of patients were documented and the patients completed DLQI and HADS on the day of clinical examination. Personal data of controls were documented and controls completed DLQI and HADS.

DLQI is the most frequently used method because it is simple and clear. Patients' direction to affect social and physical activations in the last week has been tried to be understood. It is designed on the basis of symptoms, feelings of the patient, daily activity, leisure time, school/work life, personal relationships and treatment. DLQI, consists of 10 items, each item is scored: "Very much" - score 3, "a lot" - score 2, "a little" - score 1, "not at all" and "irrelevant" - score 0. Based on their scores, five score ranges can be classified as follows: No effect at all on patient's life (0-1), a small effect on patient's life (2-5), a moderate effect on patient's life (6-10), and very large effect on patient's life (1120), extremely large effect on patient's life (21-30).

The HADS detect mood disorders in non-psychiatric hospital clinics, evaluate anxiety and depression separately and exclude symptoms to prevent physical illnesses' effects on the scores. It is quick, short and easy to answer and consists of seven anxiety items and seven depression items (14 items). Each item is responded on a four-point measure. The total score ranges from 0 to 21 points for anxiety and similarly 0 to 21 points for depression. Based on their scores, three score ranges can be categorized as follows: Normal (0-7), borderline abnormal (8-10), and abnormal (11-21).

\section{Statistical Analysis}

Statistical analysis was performed using SPSS software, version 22. Descriptive data were shown as n, percent in categorical data, and as median, interquartile range (25-75 percentile values) in scale data. Chi-square test was used to compare categorical data. The normality of data was tested using a Kolmogorov-Smirnov test. Mann-Whitney $U$ test and Kruskal-Wallis test was used for not having a normal distribution. A p value of less than 0.05 was considered statistically significant.

\section{RESULTS}

This study encompassed 70 RAS cases (35 males and 35 females) with a mean age of $29.6 \pm 10.8$ years and 70 controls (38 males and 32 females) with a mean age of $29.3 \pm 10.6$ years. There were no differences in terms of age, gender, marital status, and educational level (Table 1).

Table 1. Demographic characteristics of groups

\begin{tabular}{|c|c|c|c|c|c|c|}
\hline \multirow[b]{2}{*}{ Parameter } & \multirow[b]{2}{*}{ Category } & \multicolumn{2}{|c|}{ Patients } & \multicolumn{2}{|c|}{ Controls } & \multirow{2}{*}{$\mathbf{p}^{\mathrm{a}}$} \\
\hline & & n & $\%$ & n & $\%$ & \\
\hline \multirow{2}{*}{ Age } & $\leq 30$ years & 42 & 60.0 & 44 & 63.8 & \multirow{2}{*}{0.647} \\
\hline & $>30$ years & 28 & 40.0 & 25 & 36.2 & \\
\hline \multirow{2}{*}{ Gender } & Female & 35 & 50.0 & 38 & 54.3 & \multirow{2}{*}{0.612} \\
\hline & Male & 35 & 50.0 & 32 & 45.7 & \\
\hline \multirow{2}{*}{$\begin{array}{l}\text { Marital } \\
\text { status }\end{array}$} & Single & 32 & 45.7 & 41 & 58.6 & \multirow{2}{*}{0.128} \\
\hline & Married & 38 & 54.3 & 29 & 41.4 & \\
\hline \multirow{3}{*}{$\begin{array}{l}\text { Educational } \\
\text { level }\end{array}$} & Primary school & 21 & 30.0 & 11 & 15.7 & \multirow{3}{*}{0.094} \\
\hline & High school & 21 & 30.0 & 30 & 42.9 & \\
\hline & University & 28 & 40.0 & 29 & 41.4 & \\
\hline \multirow{3}{*}{ Occupation } & Student & 22 & 31.4 & 19 & 27.1 & \multirow{3}{*}{0.593} \\
\hline & Housewife & 16 & 22.9 & 13 & 18.6 & \\
\hline & Other & 32 & 45.7 & 38 & 54.3 & \\
\hline
\end{tabular}


Sixty (85.7\%) of patients were in the active phase and 10 (14.3\%) of patients were in remission period during examination. 36 (51.4\%) of the patients had disease for five years and more (Table 2). Most of the patients had 2 to 3 attacks per month.

DLQI scores of RAS patients ranged from 0 to 30 [interquartile range (IQR): $6.0-15.0]$; DLQI scores of controls ranged from 0 to 30 (IQR: 2.0-9.0). DLQI score was significantly higher in the patient group than the control group $(p<0.001$, Table 3, Figure 1).

HADS of patients ranged from 1 to 20 (IOR 4.0-11.0) for anxiety, 0 to 15 (IQR: 2.0-7.0) for depression. Similarly, the control group's HAD scores ranged from 1 to 18 (IQR: 5.0-10.0) for anxiety, 0 to 14 (IQR: 2.0-8.0) for depression. There was no statistically significant difference between two groups with respect to both anxiety and depression scores ( $p=0.912, p=0.978$ ) (Table 3).

Anxiety HADS of female patients was higher than that of male patients (IQR: $5.0-12.0$ vs. 4.0-9.0, $\mathrm{p}=0.019$ ). There was no relationship between gender and DLQI and depression scores as well as age, marital status, education status, family history and DLQI and HADS (Table 4).

DLQI score of the patients with RAS during the active phase was higher than that for those with RAS during the remission period (IQR: $6.5-16.0$ vs. 2.0-10.0, $p=0.039$, Figure 2). There was

Table 2. Detailed characteristics of patients

\begin{tabular}{|l|l|l|l|}
\hline Parameter & Category & $\mathbf{n}$ & $\%$ \\
\hline \multirow{3}{*}{ Family history } & Positive (+) & 42 & 60.0 \\
\cline { 2 - 4 } & Negative (-) & 28 & 40.0 \\
\hline \multirow{3}{*}{ Mean duration of disease (year) } & $<5$ & 34 & 48.6 \\
\cline { 2 - 4 } & $\geq 5$ & 36 & 51.4 \\
\hline \multirow{3}{*}{ Frequency of attacks (per year) } & $\leq 12$ & 14 & 20.0 \\
\cline { 2 - 4 } & $13-36$ & 34 & 48.6 \\
\cline { 2 - 4 } & $>36$ & 22 & 31.4 \\
\hline \multirow{3}{*}{ Presence of oral ulcer } & Active phase & 60 & 85.7 \\
\cline { 2 - 4 } & Remission period & 10 & 14.3 \\
\hline
\end{tabular}

Table 3. The statistical analysis of scale scores in RAS patients and controls

\begin{tabular}{|c|c|c|c|c|c|}
\hline \multirow[b]{2}{*}{ Parameter } & \multicolumn{2}{|l|}{ Patients } & \multicolumn{2}{|l|}{ Controls } & \multirow{2}{*}{$p^{a}$} \\
\hline & Median & $\mathrm{IQR}$ & Median & IQR & \\
\hline DLQI & 10.0 & $6.0-15.0$ & 5.0 & $2.0-9.0$ & $<0.001$ \\
\hline HADS-A & 7.0 & $4.0-11.0$ & 7.0 & $5.0-10.0$ & 0.912 \\
\hline HADS-D & 5.0 & $2.0-7.0$ & 5.0 & $2.0-8.0$ & 0.978 \\
\hline
\end{tabular}

${ }^{a}$ Mann-Whitney U test, IQR: Interquartile range, DLQI: Dermatology life quality index, HADS-A: Hospital anxiety and depression scale anxiety, HADS-D: Hospital anxiety and depression scale depression, RAS: Recurrent aphthous stomatitis

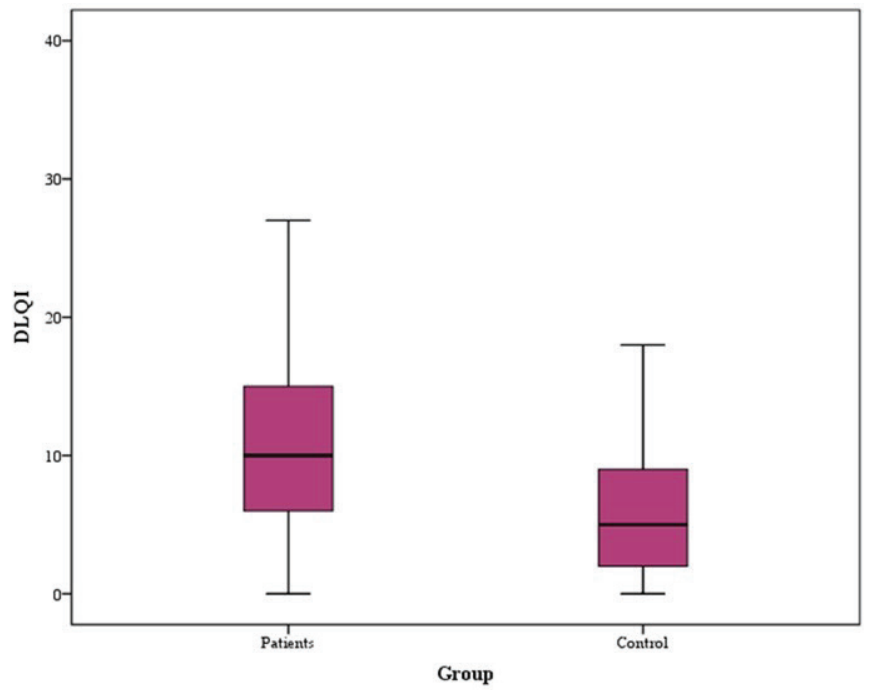

Figure 1. DLQI scores of RAS patients and controls DLQI: Dermatology life quality index, RAS: Recurrent aphthous stomatitis

no difference between the patients during the active phase and the patients during the remission period in terms of scores of anxiety and depression. No difference was found between the duration of disease and frequency of attacks, and scale scores (Table 4).

\section{DISCUSSION}

Our study is a prospective and comparative evaluation of the quality of life, anxiety and depression status of RAS patients in Turkey by using DLQI and HADS. There are many studies in the literature about the relationship between quality of life, anxiety and depression and RAS. Most of the studies assessed quality of life by using the oral health impact profile (OHIP-14) (17-19). DLQI is the most frequently used method worldwide in dermatology clinics. HADS, the social readjustment rating scale, structured clinical interview for DSM-IV clinical version, self-rating anxiety scale, general health questionnaire scale, Spielberger statetrait anxiety inventory (STAI), Hamilton's anxiety rating scale (HARS) and Hamilton's depression rating scale (HDRS), Lipp's inventory of stress symptoms (LSSI), Beck anxiety inventory and Beck depression inventory-II are used for the evaluation of the anxiety and depression in patients with oral disease, particularly RAS $(8,14,20,21)$. We assessed the state of anxiety and depression in RAS patients by using HADS because it excludes somatic symptoms, which prevent the effects of physical illnesses on the scores $(14,22)$.

Yang et al. (18), analyzed psychological problems of the patients with RAS, oral lichen planus (OLP) and burning mouth syndrome (BMS) using OHIP-14 and HADS. They reported that patients with RAS, OLP, and BMS had lower quality of life and higher levels of 


\begin{tabular}{|c|c|c|c|c|c|c|c|}
\hline \multirow[b]{2}{*}{ Parameter } & \multirow[b]{2}{*}{ Category } & \multicolumn{2}{|l|}{ DLQI } & \multicolumn{2}{|l|}{ HADS-A } & \multicolumn{2}{|l|}{ HADS-D } \\
\hline & & Median (IQR) & $\mathbf{p}$ & Median (IQR) & $\mathbf{p}$ & Median (IQR) & $p$ \\
\hline \multirow[t]{2}{*}{ Age $^{a}$ (year) } & $\leq 30$ & $9.5(6.0-14.0)$ & \multirow{2}{*}{0.986} & $7.0(4.0-11.0)$ & \multirow{2}{*}{0.750} & $5.0(2.0-7.0)$ & \multirow{2}{*}{0.157} \\
\hline & $>30$ & $10.5(5.0-16.5)$ & & $6.5(5.0-10.5)$ & & $6.0(3.0-9.5)$ & \\
\hline \multirow[t]{2}{*}{ Gender ${ }^{\mathrm{a}}$} & Female & $11.0(8.0-16.0)$ & \multirow{2}{*}{0.070} & $8.0(5.0-12.0)$ & \multirow{2}{*}{0.019} & $6.0(3.0-8.0)$ & \multirow{2}{*}{0.306} \\
\hline & Male & $8.0(4.0-15.0)$ & & $6.0(4.0-9.0)$ & & $5.0(2.0-7.0)$ & \\
\hline \multirow{2}{*}{ Marital status $^{\mathrm{a}}$} & Single & $10.5(7.5-14.0)$ & \multirow{2}{*}{0.493} & $8.0(3.5-11.0)$ & \multirow{2}{*}{0.335} & $5.0(2.5-7.5)$ & \multirow{2}{*}{0.817} \\
\hline & Married & $9.0(5.0-17.0)$ & & $6.0(4.0-9.0)$ & & $5.5(2.0-7.0)$ & \\
\hline \multirow{3}{*}{ Educational level $^{b}$} & Primary school & $11.0(6.0-17.0)$ & \multirow{3}{*}{0.232} & $8.0(5.0-11.0)$ & \multirow{3}{*}{0.655} & $7.0(4.0-12.0)$ & \multirow{3}{*}{0.168} \\
\hline & High school & $9.0(5.0-11.0)$ & & $6.0(4.0-10.0)$ & & $5.0(2.0-7.0)$ & \\
\hline & University & $10.5(6.0-19.5)$ & & $6.5(5.0-9.0)$ & & $5.0(2.0-7.0)$ & \\
\hline \multirow{2}{*}{ Family history ${ }^{\mathrm{a}}$} & Positive & $10.5(5.0-16.0)$ & \multirow{2}{*}{0.666} & $6.5(4.0-10.0)$ & \multirow{2}{*}{0.904} & $5.5(2.0-7.0)$ & \multirow{2}{*}{0.837} \\
\hline & Negative & $9.0(6.0-13.5)$ & & $7.0(4.0-11.0)$ & & $5.0(2.0-8.0)$ & \\
\hline \multirow{2}{*}{ Duration of disease (year) ${ }^{\mathrm{a}}$} & $<5$ & $10.0(6.0-14.0)$ & \multirow{2}{*}{0.906} & $6.5(4.0-11.0)$ & \multirow{2}{*}{0.710} & $5.0(3.0-7.0)$ & \multirow{2}{*}{0.976} \\
\hline & $\geq 5$ & $9.5(5.0-18.0)$ & & $7.0(5.0-10.0)$ & & $5.5(2.0-7.5)$ & \\
\hline \multirow{3}{*}{ Frequency of attacks ${ }^{b}$ (per year) } & $\leq 12$ & $8.0(5.0-14.0)$ & \multirow{3}{*}{0.315} & $5.5(4.0-9.0)$ & \multirow{3}{*}{0.419} & $5.0(2.0-7.0)$ & \multirow{3}{*}{0.263} \\
\hline & $13-36$ & $10.5(5.0-13.0)$ & & $6.5(4.0-11.0)$ & & $5.0(2.0-7.0)$ & \\
\hline & $>36$ & $11.0(8.0-18.0)$ & & $8.5(4.0-11.0)$ & & $7.0(4.0-10.0)$ & \\
\hline \multirow{2}{*}{ Oral ulcer $^{\mathrm{a}}$} & Active phase & $11.0(6.5-16.0)$ & \multirow{2}{*}{0.039} & $7.0(4.5-11.0)$ & 0004 & $5.0(2.5-8.0)$ & $0: 967$ \\
\hline & Remission period & $5.0(2.0-10.0)$ & & $5.0(2.0-6.0)$ & 0.007 & $5.5(2.0-6.0)$ & 0.701 \\
\hline
\end{tabular}

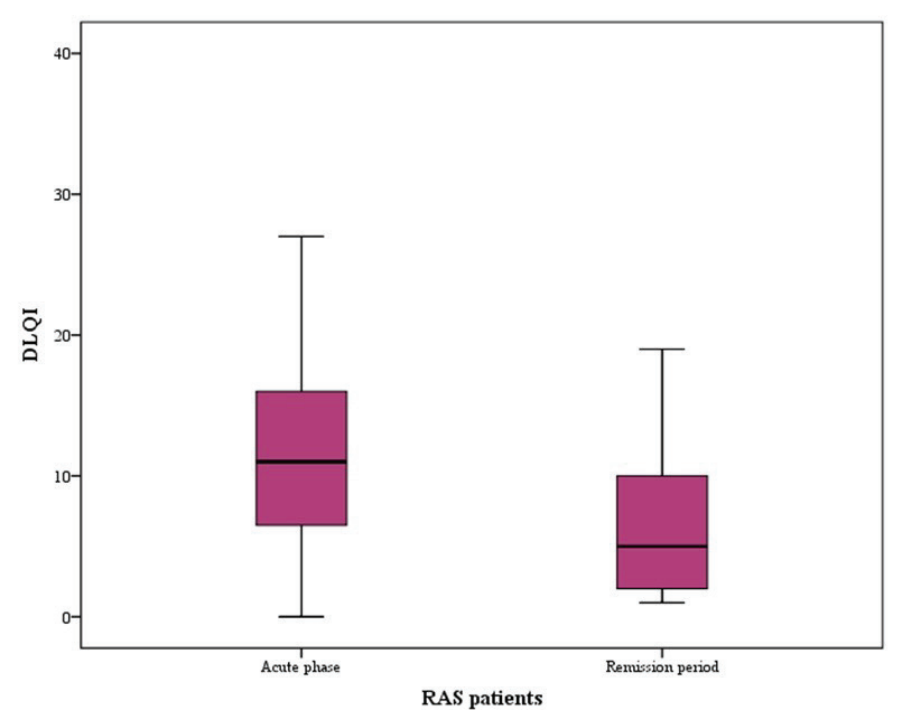

Figure 2. DLQI scores of the patients during active phase and the patients during remission period DLQI: Dermatology life quality index

anxiety and depression. Suresh et al. (23), estimated the validity of other oral mucosal diseases in anxiety and depression patients. In the study, there was a statistically significant difference in oral diseases in patients with anxiety and depression compared to the control group. They detected RAS with a rate of $12 \%$ in the patient group and $2.2 \%$ in the control group and suggested that anxiety and depression is a risk factor for RAS. Nadendla et al. (13), compared RAS patients with controls by using HARS and reported that the mean anxiety scores of the RAS group were significantly higher. They suggested anxiety may be involved in the etiopathogenesis of RAS and psychological support is beneficial for patients with RAS. Similarly, Cardoso et al. (24), assessed anxiety levels of RAS patients by using LSSI and BAI and they reported that higher levels of anxiety were associated with RAS. Gallo et al. (25), proposed that psychological conditions might play a role as a trigger or a modifying factor in RAS rather than being a cause of the disease.

The authors who reported that stress was related to the etiopathogenesis of RAS have suggested some mechanisms whereby stress might result in RAS. Increasing the number of leukocytes in the sites of inflammation due to immune system activity, increased production of inflammatory cytokines due to oxidative stress, increased salivary cortisol levels and trauma associated with biting the oral mucosa in stressful times are the proposed mechanisms $(11,12,26,27)$.

Polat et al. (20), evaluated the state of anxiety and depression by using HARS and HDRS and found no difference between the 
patients and controls for anxiety, but there was a significant difference between the groups in terms of depression. Zwiri (14), evaluated the quality of life, anxiety, and depression by using OHIP-14 and HADS in patients and controls. The patients had inferior quality of life compared to controls, and there was no difference between scores of HADs among both groups, as in our study. The author suggested that RAS affects quality of life negatively. However, stressful conditions such as anxiety and depression were not related to quality of life in patients with RAS. Sherman et al. (15), examined the relationships between physical characteristics and psychologic symptoms in RAS patients and reported that the pain intensity was not affected by psychological characteristics. Picek et al. (16), reported similar results with our study by using STAI and BDI-II, and they found no difference in the level of depression and anxiety between the groups. They concluded that psychological disturbance is irrelevant with the occurrence of RAS.

\section{Study Limitations}

The limitation of our study was being performed in a single center. Psychological conditions may vary with the cultural structure and socioeconomic status of societies. Therefore, multicenter studies involving wider populations are needed to clarify whether anxiety and depression play a definitive role in the etiopathogenesis of RAS.

\section{CONCLUSION}

The results of our study showed that patients with RAS had impaired quality of life and were particularly more affected negatively in the acute phase because of pain during normal life activities such as eating and speaking. Because of the absence of relationship between RAS and psychological conditions, we suggest that both anxiety and depression may not be associated with the etiopathogenesis of RAS. Hence, studies on larger patient groups should be conducted.

\section{Ethics}

Ethics Committee Approval: Ataturk University Faculty of Medicine Ethics Committee approved the study (number of meetings: 6 , decision no: 10 , date: 30.11.2017).

Informed Consent: Consent was received.

Peer-review: Externally peer-reviewed.

\section{Authorship Contributions}

Surgical and Medical Practices: Ü.Ö., Concept: Ü.Ö., F.Ö., Design: Ü.Ö., F.Ö., Data Collection or Processing: Ü.Ö., F.Ö., O.K., Analysis or Interpretation: Ü.Ö., O.K., Ş.Ö., Literature Search: Ü.Ö., Writing: Ü.Ö., F.Ö., O.K.

Conflict of Interest: No conflict of interest was declared by the authors.

Financial Disclosure: The authors declared that this study received no financial support.

\section{REFERENCES}

1. Hu X, Pan H, He W, Hua H, Yan Z. Evaluation of the content quality of websites for recurrent aphthous ulcers and oral lichen planus. BMC Oral Health 2017;17:170.

2. Chiang CP, Yu-Fong Chang J, Wang YP, Wu YH, Wu YC, Sun A. Recurrent aphthous stomatitis - Etiology, serum autoantibodies, anemia, hematinic deficiencies, and management. J Formos Med Assoc 2019;118:1279-89.

3. Scully C, Gorsky M, Lozada-Nur F. The diagnosis and management of recurrent aphthous stomatitis: a consensus approach. J Am Dent Assoc 2003;134:200-7.

4. McCullough MJ, Abdel-Hafeth S, Scully C. Recurrent aphthous stomatitis revisited; clinical features, associations, and new association with infant feeding practices? J Oral Pathol Med 2007;36:615-20.

5. Marakoğlu K, Sezer RE, Toker HC, Marakoğlu I. The recurrent aphthous stomatitis frequency in the smoking cessation people. Clin Oral Investig 2007;11:149-53.

6. Zhang Z, Li S, Fang H. Enzymatic antioxidants status in patients with recurrent aphthous stomatitis. J Oral Pathol Med 2017;46:817-20.

7. Bankvall M, Sjöberg F, Gale G, Wold A, Jontell M, Östman S. The oral microbiota of patients with recurrent aphthous stomatitis. J Oral Microbiol 2014;6:25739

8. Dhopte A, Naidu G, Singh-Makkad R, Nagi R, Bagde H, Jain S. Psychometric analysis of stress, anxiety and depression in patients with recurrent aphthous stomatitis-A cross-sectional survey based study. J Clin Exp Dent 2018;10:e1109-14.

9. Al-Omiri MK, Karasneh J, Lynch E. Psychological profiles in patients with recurrent aphthous ulcers. Int J Oral Maxillofac Surg 2012;41:384-8.

10. Soto Araya M, Rojas Alcayaga G, Esguep A. Association between psychological disorders and the presence of oral lichen planus, Burning mouth syndrome and recurrent aphthous stomatitis. Med Oral 2004;9:1-7.

11. Huling LB, Baccaglini L, Choquette L, Feinn RS, Lalla RV. Effect of stressful life events on the onset and duration of recurrent aphthous stomatitis. J Oral Pathol Med 2012;41:149-52.

12. Redwine L, Snow S, Mills P, Irwin M. Acute psychological stress: effects on chemotaxis and cellular adhesion molecule expression. Psychosom Med 2003;65:598-603.

13. Nadendla LK, Meduri V, Paramkusam G, Pachava KR. Relationship of salivary cortisol and anxiety in recurrent aphthous stomatitis. Indian J Endocrinol Metab 2015;19:56-9.

14. Zwiri AM. Anxiety, depression and quality of life among patients with recurrent aphthous ulcers. J Contemp Dent Pract 2015;16:112-7.

15. Sherman JJ, Barach R, Whitcomb KK, Haley J, Martin MD. Pain and painrelated interference associated with recurrent aphthous ulcers. J Orofac Pain 2007;21:99-106. 
16. Picek P, Buljan D, Rogulj AA, Stipetić-Ovcarićek J, Catić A, Plestina S et al. Psychological status and recurrent aphthous ulceration. Coll Antropol 2012;36:157-9.

17. Hapa A, Aksoy B, Polat M, Aslan U, Atakan N. Does recurrent aphthous stomatitis affect quality of life? A prospective study with 128 patients evaluating different treatment modalities. J Dermatolog Treat 2011;22:215-20.

18. Yang C, Liu L, Shi H, Zhang Y. Psychological problems and quality of life of patients with oral mucosal diseases: a preliminary study in Chinese population. BMC Oral Health 2018;18:226.

19. Kürklü-Gürleyen E, Öğüt-Erişen M, Çakır O, Uysal Ö, Ak G. Quality of life in patients with recurrent aphthous stomatitis treated with a mucoadhesive patch containing citrus essential oil. Patient Prefer Adherence 2016;10:967-73.

20. Polat C, Düzer S, Ayyıldız H, Seç S, Aksoy N, Sakallığlu Ö, et al. Association between anxiety, depression, and salivary cortisol levels in patients with recurrent aphthous stomatitis. Turk Arch Otorhinolaryngol. 2018;56:166-9.

21. Maina G, Albert U, Gandolfo S, Vitalucci A, Bogetto F. Personality disorders in patients with burning mouth syndrome. J Pers Disord 2005; 19:84-93.
22. Aylard PR, Gooding JH, McKenna PJ, Snaith RP. A validation study of three anxiety and depression self-assessment scales. J Psychosom Res 1987;31:261-8.

23. Suresh KV, Shenai P, Chatra L, Ronad YA, Bilahari N, Pramod RC, et al. Oral mucosal diseases in anxiety and depression patients: Hospital based observational study from south India. J Clin Exp Dent 2015;7:e959.

24. Cardoso JA, Dos Santos Junior AA, Nunes ML, de Figueiredo MA, Cherubini K, Salum FG. Salivary alpha-amylase enzyme, psychological disorders, and life quality in patients with recurrent aphthous stomatitis. Int J Dent 2017;2017:5269856.

25. Gallo Cde B, Mimura MA, Sugaya NN. Psychological stress and recurrent aphthous stomatitis. Clinics (Sao Paulo) 2009;64:645-8.

26. Albanidou-Farmaki E, Poulopoulos AK, Epivatianos A, Farmakis K, Karamouzis M, Antoniades D. Increased anxiety level and high salivary and serum cortisol concentrations in patients with recurrent aphthous stomatitis. Tohoku J Exp Med 2008;214:291-6.

27. Cağlayan F, Miloglu O, Altun O, Erel O, Yilmaz AB. Oxidative stress and myeloperoxidase levels in saliva of patients with recurrent aphthous stomatitis. Oral Dis 2008;14:700-4. 